\title{
New acetylenic derivatives of betulin and betulone, synthesis and cytotoxic activity
}

\author{
Ewa Bębenek $^{1} \cdot$ Monika Kadela-Tomanek $^{1} \cdot$ Elwira Chrobak $^{1} \cdot$ Joanna Wietrzyk $^{2}$ • \\ Joanna Sadowska ${ }^{2} \cdot$ Stanisław Boryczka ${ }^{1}$
}

Received: 23 March 2016 / Accepted: 8 August 2016 / Published online: 1 September 2016

(C) The Author(s) 2016; This article is published with open access at Springerlink.com

\begin{abstract}
Betulin 1 and its semisynthetic derivatives exhibit a cytotoxic activity toward various cancer cell lines. These compounds are a promising and potential anticancer candidates. A series of betulin derivatives was prepared and tested for the antiproliferative activity in vitro against T47D breast cancer, CCRF/CEM leukemia, HL-60 promyelocytic leukemia, SW707 colorectal, murine P388 leukemia, as well as BALB3T3 normal fibroblasts cell lines. Cisplatin and betulin 1 were used as a reference compounds. Some derivatives of betulin showed a higher cytotoxic activity than the parent compound $\mathbf{1}$. Two derivatives (5 and 17) were 24-fold potent than betulin 1 against the human promyelocytic leukemia cell line (HL-60), with an $\mathrm{IC}_{50}$ value of $0.3 \mu \mathrm{g} / \mathrm{mL}$.
\end{abstract}

Keywords Betulin $\cdot$ Betulone $\cdot$ Synthesis $\cdot$ Cytotoxic activity $\cdot$ Lipophilicity

\section{Introduction}

Betulin (lup-20(29)-ene-3 $\beta, 28$-diol) $\mathbf{1}$ is a pentacyclic triterpene of the lupane type which is isolated from bark of

Ewa Bębenek

ebebenek@sum.edu.pl

1 Department of Organic Chemistry, Medical University of Silesia in Katowice, School of Pharmacy with the Division of Laboratory Medicine in Sosnowiec, 4 Jagiellońska Str., Sosnowiec 41-200, Poland

2 Department of Experimental Oncology, Polish Academy of Sciences, Ludwik Hirszfeld Institute of Immunology and Experimental Therapy, 12 R. Weigla Str., Wrocław 53-114, Poland white birch species (Fig. 1). The compound $\mathbf{1}$ has three active positions in its structure, namely the primary hydroxyl group at C-28, the secondary group at C-3 and the isopropenyl side chain at $\mathrm{C}-19$. It's possible to make a chemical modification of these positions to obtain new betulin derivatives with important biological properties such as antitumor, antiviral, antimicrobial, anti-inflammatory, as well as hepatoprotective activities (Alakurtti et al., 2006; Tolstikov et al., 2005).

Betulone (lup-20(29)-en-28-ol-3-one) 2 similarly to betulin 1 represents a class of pentacyclic triterpenes which can be isolated from various plants (Fig. 1) (Diouf et al., 2009; Liu et al., 2012; Reyes et al., 2006). The content of betulone $\mathbf{2}$ in the native plant material is very low, therefore the compound 2 was obtained by oxidation or biotransformation of naturally occurring betulin $\mathbf{1}$ (Grishko et al., 2013; Hase et al., 1981; Mao et al., 2012). Despite the fact that betulone 2 has been isolated from Betula lenta in 1991 (Cole et al., 1991), the crystal structure of this compound was determined for the first time in 2013 (Boryczka et al., 2013a).

It has already been reported that betulone 2 possess interesting pharmacological activities such as anti-

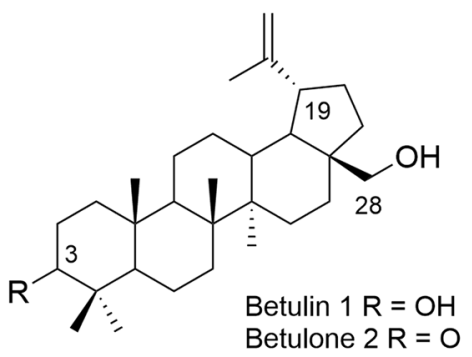

Fig. 1 Chemical structure of betulin $\mathbf{1}$ and betulone $\mathbf{2}$ 
leishmanial, anti-inflammatory, and aniparasitic against Plasmodium falciparum and Trypanosoma brucei rhodesiense (Alakurtti et al., 2010; Gachet et al., 2011; Reyes et al., 2006). Triterpene 2 exhibited also antifouling activity against cyprid larvae of the barnacle Balanus albicostatus with the $\mathrm{EC}_{50}$ value $8.73 \mu \mathrm{g} / \mathrm{mL}$ slightly higher than betulin 1 (Chen et al., 2011). The compound $\mathbf{2}$ demonstrated almost the same protective effects as betulin $\mathbf{1}$ against the cytotoxicity of cadmium at high concentrations (Hiroya et al., 2002). Betulone 2 with the carbonyl group at C-3 position showed anticancer effect on mouse melanoma (B16 2F2) cell line with the $\mathrm{IC}_{50}$ value $29.3 \mu \mathrm{M}$ (Hata et al., 2002). Additionally, the compound $\mathbf{2}$ and its derivatives showed in vitro cytotoxic activity against different cancer cell lines like stomach (MGC-803), breast (Bcap-37, MCF-7), prostate (PC3), melanoma (SK-MEL-2, A-375), medulloblastoma (Dayo), glioblastoma (LN-229), ovarian carcinoma (OVCAR-3), and colon carcinoma (HT-29) (Koohang et al., 2009; Liu et al., 2012; Mar et al., 2009). Derivatives of betulone containing 3 '-substituted glutaryl groups at C-28 position represent a new class of anti-HIV agents. These compounds exhibited anti-HIV activity with $\mathrm{EC}_{50}$ values in the range of 4.3-10.0 $\mu \mathrm{M}$ (Sun et al., 1998a; Sun et al., 1998b).

We have previously described the synthesis and evaluation of cytotoxicity of betulin derivatives containing one or two acetylenic groups at the C-3 and/or C- 28 positions. Our studies showed, that the derivative of betulin with a propynoyl group at C-28 position, has strong cytotoxic effects against human leukemia (CCRF/CEM) and murine leukemia (P388) cancer cells. Moreover, 28-O-propynoylbetulin induces apoptosis in human melanoma (G-361) cells via caspase-3 activation (Boryczka et al., 2013b; Orchel et al., 2014).

Continuing our research project on the development of anticancer agents, we synthesized new compounds, in order to obtain more information about the influence of alkane, alkene, and alkyne moiety at the C- 28 position on antiproliferative activity in the group of betulin and betulone derivatives.

\section{Materials and methods}

\section{Chemistry}

Melting points of betulin derivatives were obtained in open capillary tubes on a Boetius melting point apparatus without correction. Nuclear magnetic resonance (NMR) (600/150 $\mathrm{MHz}$ ) spectra were measured in $\mathrm{CDCl}_{3}$ as solvent on a Bruker Avance III 600 spectrometer. The chemical shifts values are reported in ppm $(\delta)$ and the coupling constants $(J)$ are presented in Hertz. The spin multiplicities are given as singlet (s), doublet (d), triplet (t), q (quartet), and multiplet $(\mathrm{m})$. Mass spectra were measured under EI conditions on a Finnigan MAT 95 spectrometer. Infrared spectra $(\mathrm{KBr}$, pellet) were recorded using the IRAffinity-1 Shimadzu spectrometer and reported in wave number $\left(\mathrm{cm}^{-1}\right)$. The progress of all reactions were monitored by thin layer chromatography (TLC) on silica gel $60254 \mathrm{~F}$ plates using a mixture of chloroform and ethanol $(40: 1, \mathrm{v} / \mathrm{v})$ as an eluent. The spots were visualized by spraying with a solution of 5 $\%$ sulfuric acid and then heating to $100{ }^{\circ} \mathrm{C}$. Purification of the new compounds was carried out by column chromatography (silica gel $60,<63 \mu \mathrm{m}$, Merk) using a mixture of chloroform and ethanol $(40: 1, \mathrm{v} / \mathrm{v})$ as an eluent. All solvents for reactions were dried and purified prior to use.

The synthesis and spectral data of the compounds $\mathbf{3}, \mathbf{5}, \mathbf{7}$, 12-14 was described previously by Boryczka et al. (2013b).

\section{General procedure for the synthesis of derivatives 4, 6, 8-9}

To a mixture of betulin $1(0.44 \mathrm{~g}, 1 \mathrm{mmol})$ and 2-propenoic acid $(0.08 \mathrm{~g}, 1.10 \mathrm{mmol}), 3$-cyclopropyl-2-propynoic acid $(0.12 \mathrm{~g}, 1.10 \mathrm{mmol}), 2$-butenoic acid $(0.09 \mathrm{~g}, 1.10 \mathrm{mmol})$ or 2-butynoic acid $(0.9 \mathrm{~g}, 1.10 \mathrm{mmol})$ in dichloromethane (5 $\mathrm{mL}$ ) was added slowly a solution of dicyclohexylcarbodiimide $\quad(0.23 \mathrm{~g}, \quad 1.12 \mathrm{mmol}), \quad$ and $\quad 4-$ dimethylaminopyridine $(0.01 \mathrm{~g}, 0.08 \mathrm{mmol})$ in dichloromethane $(1 \mathrm{~mL})$ at $-10^{\circ} \mathrm{C}$ temperature. The reaction was stirred under argon atmosphere at $-10^{\circ} \mathrm{C}$ temperature for 5 $\mathrm{h}$, and then was allowed to warm to room temperature and stirred overnight. The progress of the reaction was monitored by TLC until completion and then filtered. The solvent was removed under reduced pressure and the residue was purified by silica gel column chromatography (chloroform/ethanol 40:1, v/v).

28-O-(2-Propenoyl)betulin (4) Yield $74 \%$; mp $117-121^{\circ} \mathrm{C}$; $R_{\mathrm{f}} 0.44$ (chloroform/ethanol, 40:1, v/v); IR (KBr) $\nu$ max 3445 , 2939, 1723, 1456, $1269 \mathrm{~cm}^{-1} ;{ }^{1} \mathrm{H}$ NMR $\left(600 \mathrm{MHz}, \mathrm{CDCl}_{3}\right): \delta$ $6.42\left(1 \mathrm{H}, \mathrm{m}, \mathrm{CH}=\underline{\mathrm{CH}_{2}}\right), 6.15\left(1 \mathrm{H}, \mathrm{m}, \underline{\mathrm{CH}}=\mathrm{CH}_{2}\right), 5.84(1 \mathrm{H}, \mathrm{m}$, $\left.\mathrm{CH}=\underline{\mathrm{CH}_{2}}\right), 4.71(1 \mathrm{H}, \mathrm{s}, \mathrm{H}-29), 4.61(1 \mathrm{H}, \mathrm{s}, \mathrm{H}-29), 4.36(1 \mathrm{H}, \mathrm{d}$, $J=10.8 \mathrm{~Hz}, \mathrm{H}-28), 3.95(1 \mathrm{H}, \mathrm{d}, J=10.8 \mathrm{~Hz}, \mathrm{H}-28), 3.20(1 \mathrm{H}$, m, H-3), $2.49(1 \mathrm{H}, \mathrm{m}, \mathrm{H}-19), 1.67\left(3 \mathrm{H}, \mathrm{s}, \mathrm{CH}_{3}\right), 1.06(3 \mathrm{H}, \mathrm{s}$, $\left.\mathrm{CH}_{3}\right), 0.98\left(3 \mathrm{H}, \mathrm{s}, \mathrm{CH}_{3}\right), 0.96\left(3 \mathrm{H}, \mathrm{s}, \mathrm{CH}_{3}\right), 0.84\left(3 \mathrm{H}, \mathrm{s}, \mathrm{CH}_{3}\right)$, $0.77\left(3 \mathrm{H}, \mathrm{s}, \mathrm{CH}_{3}\right) ;{ }^{13} \mathrm{C}$ NMR $\left(150 \mathrm{MHz}, \mathrm{CDCl}_{3}\right): \delta 166.7$ $(\mathrm{O}-\mathrm{C}=\mathrm{O}), 150.2$ (C-20), 130.5, 128.6, 109.9 (C-29), 79.0 (C3), 62.8 (C-28), 55.3, 50.4, 48.8, 47.7, 46.5, 42.7, 40.9, 38.9, 38.7, 37.6, 37.1, 34.6, 34.2, 29.8, 29.6, 28.0, 27.4, 27.1, 25.2, $20.8,19.1,18.3,16.1,16.0,15.4,14.8$; EIMS $m / z 496[\mathrm{M}]^{+}$ (14), 189 (100).

28-O-(3-Cyclopropyl-2-propynoyl)betulin (6) Yield 49\%; mp $108-113{ }^{\circ} \mathrm{C} ; R_{\mathrm{f}} 0.44$ (chloroform/ethanol, 40:1, v/v); IR (KBr) $\nu \max 3475,2941,2228,1707,1454,1258 \mathrm{~cm}^{-1} ;{ }^{1} \mathrm{H}$ NMR (600 MHz, CDCl $)$ ): $\delta 4.68(1 \mathrm{H}, \mathrm{s}, \mathrm{H}-29), 4.58(1 \mathrm{H}, \mathrm{s}, \mathrm{H}-$ 29), $4.31(1 \mathrm{H}, \mathrm{d}, J=10.8 \mathrm{~Hz}, \mathrm{H}-28), 3.93(1 \mathrm{H}, \mathrm{d}, J=10.8 \mathrm{~Hz}$, 
H-28), 3.18 (1H, m, H-3), 2.42 (1H, m, H-19), 1.67 (3H, s, $\left.\mathrm{CH}_{3}\right), 1.01$ (3H, s, $\left.\mathrm{CH}_{3}\right), 0.97\left(3 \mathrm{H}, \mathrm{s}, \mathrm{CH}_{3}\right), 0.96\left(3 \mathrm{H}, \mathrm{s}, \mathrm{CH}_{3}\right)$, 0.92-0.91 (5H, m, CH, CH $), 0.82\left(3 \mathrm{H}, \mathrm{s}, \mathrm{CH}_{3}\right), 0.77(3 \mathrm{H}, \mathrm{s}$, $\left.\mathrm{CH}_{3}\right) ;{ }^{13} \mathrm{C}$ NMR $\left(150 \mathrm{MHz}, \mathrm{CDCl}_{3}\right): \delta 154.5(\mathrm{O}-\mathrm{C}=\mathrm{O}), 150.1$ (C-20), 109.9 (C-29), 93.3, 78.9 (C-3), 68.6 (C-28), 64.1, 55.3, 50.4, 48.8, 47.7, 46.4, 42.7, 40.9, 38.9, 38.7, 37.6, 37.1, 34.5, $34.2,29.7,29.5,28.0,27.4,27.0,25.2,20.8,19.1,18.3,16.1$, 16.0, 15.3, 14.8, 9.2, 1.1, -0.6; EIMS $\mathrm{m} / z 534[\mathrm{M}]^{+}$(18), 189 (100).

28-O-(2-Butenoyl)betulin (8) Yield $57 \%$; mp $182-184{ }^{\circ} \mathrm{C}$; $\mathrm{R}_{\mathrm{f}} 0.45$ (chloroform/ethanol, 40:1, v/v); $\mathrm{IR}(\mathrm{KBr}) \nu$ max 3560 , 2945, 1707, 1443, $1195 \mathrm{~cm}^{-1} ;{ }^{1} \mathrm{H}$ NMR (600 MHz, $\left.\mathrm{CDCl}_{3}\right): \delta$ $7.00\left(1 \mathrm{H}, \mathrm{m}, \mathrm{CH}=\mathrm{CHCH}_{3}\right), 5.88\left(1 \mathrm{H}, \mathrm{m}, \underline{\mathrm{CH}}=\mathrm{CHCH}_{3}\right), 4.72$ $(1 \mathrm{H}, \mathrm{s}, \mathrm{H}-29), 4.61(1 \mathrm{H}, \mathrm{s}, \mathrm{H}-29), 4.34(1 \mathrm{H}, \mathrm{d}, J=10.8 \mathrm{~Hz}, \mathrm{H}-$ 28), $3.93(1 \mathrm{H}, \mathrm{d}, J=10.8 \mathrm{~Hz}, \mathrm{H}-28), 3.21(1 \mathrm{H}, \mathrm{m}, \mathrm{H}-3), 2.48$ $(1 \mathrm{H}, \mathrm{m}, \mathrm{H}-19), 1.91\left(3 \mathrm{H}, \mathrm{m}, \mathrm{CH}=\mathrm{CHCH}_{3}\right), 1.68\left(3 \mathrm{H}, \mathrm{s}, \mathrm{CH}_{3}\right)$, $1.06\left(3 \mathrm{H}, \mathrm{s}, \mathrm{CH}_{3}\right), 1.00\left(3 \mathrm{H}, \mathrm{s}, \mathrm{CH}_{3}\right), 0.99\left(3 \mathrm{H}, \mathrm{s}, \mathrm{CH}_{3}\right), 0.85$ $\left(3 \mathrm{H}, \mathrm{s}, \mathrm{CH}_{3}\right), 0.71\left(3 \mathrm{H}, \mathrm{s}, \mathrm{CH}_{3}\right) ;{ }^{13} \mathrm{C} \mathrm{NMR}\left(150 \mathrm{MHz}, \mathrm{CDCl}_{3}\right)$ : $\delta 167.0(\mathrm{O}-\mathrm{C}=\mathrm{O}), 150.2(\mathrm{C}-20), 144.4,122.9,109.8(\mathrm{C}-29)$, 78.9 (C-3), 62.4 (C-28), 55.3, 50.4, 48.9, 47.7, 46.5, 42.7, 40.9, $38.9,38.7,37.6,37.2,34.6,34.2,29.9,29.7,28.0,27.4,27.1$, 25.2, 20.8, 19.2, 18.3, 16.1, 16.0, 15.4, 14.8, 3.7; EIMS $\mathrm{m} / \mathrm{z}$ $510[\mathrm{M}]^{+}(14), 189$ (100).

28-O-(2-Butynoyl)betulin (9) Yield 52\%; m.p. $111-113^{\circ} \mathrm{C}$; $R_{\mathrm{f}} 0.44$ (chloroform/ethanol, 40:1, v/v); IR (KBr) $\nu \max 3482$, 2942, 2245, 1709, 1457, $1248 \mathrm{~cm}^{-1}$; ${ }^{1} \mathrm{H}$ NMR $(600 \mathrm{MHz}$, $\left.\mathrm{CDCl}_{3}\right): \delta 4.69(1 \mathrm{H}, \mathrm{s}, \mathrm{H}-29), 4.59(1 \mathrm{H}, \mathrm{s}, \mathrm{H}-29), 4.33(1 \mathrm{H}, \mathrm{d}$, $J=10.8 \mathrm{~Hz}, \mathrm{H}-28), 3.95(1 \mathrm{H}, \mathrm{d}, J=10.8 \mathrm{~Hz}, \mathrm{H}-28), 3.16(1 \mathrm{H}$, m, H-3), 2.42 (1H, m, H-19), 1.99 (3H, s, $\left.\mathrm{C} \equiv \mathrm{CCH}_{3}\right), 1.68(3 \mathrm{H}$, s, $\left.\mathrm{CH}_{3}\right), 1.02\left(3 \mathrm{H}, \mathrm{s}, \mathrm{CH}_{3}\right), 0.98\left(3 \mathrm{H}, \mathrm{s}, \mathrm{CH}_{3}\right), 0.97(3 \mathrm{H}, \mathrm{s}$, $\left.\mathrm{CH}_{3}\right), 0.82\left(3 \mathrm{H}, \mathrm{s}, \mathrm{CH}_{3}\right), 0.76\left(3 \mathrm{H}, \mathrm{s}, \mathrm{CH}_{3}\right) ;{ }^{13} \mathrm{C} \mathrm{NMR}(150$ $\left.\mathrm{MHz}, \mathrm{CDCl}_{3}\right): \delta 154.4(\mathrm{O}-\mathrm{C}=\mathrm{O}), 150.0(\mathrm{C}-20), 109.9(\mathrm{C}-29)$, 85.5, 79.0 (C-3), 72.5, 64.2 (C-28), 55.3, 50.4, 48.8, 47.6, 46.4, 42.7, 40.9, 38.9, 38.7, 37.6, 37.1, 34.5, 34.2, 29.7, 29.5, 28.0, 27.4, 27.0, 25.2, 20.8, 19.1, 18.3, 16.1, 16.0, 15.3, 14.8, 3.8; EIMS m/z $508[\mathrm{M}]^{+}$(22), 189 (100).

\section{General procedure for the synthesis of derivatives 10-11}

To a mixture of betulin $1(0.44 \mathrm{~g}, 1 \mathrm{mmol})$ and pyridine $(2.5 \mathrm{~mL})$ in benzene $(6 \mathrm{~mL})$ at $0-5^{\circ} \mathrm{C}$ temperature was added solution of propyl chloroformate or allyl chloroformate $(3 \mathrm{mmol})$ in benzene $(5 \mathrm{~mL})$. The reaction was stirred at $0-5{ }^{\circ} \mathrm{C}$ temperature for $4 \mathrm{~h}$. After this time the reaction was allowed to warm to room temperature and stirred overnight. The reaction mixture was diluted with 5 $\mathrm{mL}$ of chloroform and washed successively with $1 \mathrm{~N}$ sulfuric acid and water, then dried and concentrated under reduced pressure. The crude product was purified by silica gel column chromatography (chloroform/ethanol 40:1, v/v).

28-O-Propoxycarbonylbetulin (10) Yield $51 \%$. m.p. 92-95 ${ }^{\circ} \mathrm{C} ; R_{\mathrm{f}} 0.43$ (chloroform/ethanol, 40:1, v/v); IR (KBr) $\nu_{\max } 3536,2941,1743,1457,1267 \mathrm{~cm}^{-1} ;{ }^{1} \mathrm{H}$ NMR (600
$\left.\mathrm{MHz}, \mathrm{CDCl}_{3}\right): \delta 4.72(1 \mathrm{H}, \mathrm{s}, \mathrm{H}-29), 4.61(1 \mathrm{H}, \mathrm{s}, \mathrm{H}-29)$, $4.37(1 \mathrm{H}, \mathrm{d}, J=10.8 \mathrm{~Hz}, \mathrm{H}-28), 4.12(2 \mathrm{H}, \mathrm{t}, J=6.6 \mathrm{~Hz}$, $\left.\mathrm{OCH}_{2}\right), 3.94(1 \mathrm{H}, \mathrm{d}, J=10.8 \mathrm{~Hz}, \mathrm{H}-28), 3.20(1 \mathrm{H}, \mathrm{m}, \mathrm{H}-3)$, $2.46(1 \mathrm{H}, \mathrm{m}, \mathrm{H}-19), 1.73\left(2 \mathrm{H}, \mathrm{m}, \underline{\mathrm{CH}_{2}} \mathrm{CH}_{3}\right), 1.68(3 \mathrm{H}, \mathrm{s}$, $\left.\mathrm{CH}_{3}\right), 1.07\left(3 \mathrm{H}, \mathrm{s}, \mathrm{CH}_{3}\right), 1.01\left(3 \mathrm{H}, \mathrm{s}, \mathrm{CH}_{3}\right), 1.00(3 \mathrm{H}, \mathrm{s}$, $\left.\mathrm{CH}_{3}\right), 0.99\left(3 \mathrm{H}, \mathrm{t}, J=7.2 \mathrm{~Hz}, \mathrm{CH}_{2} \mathrm{CH}_{3}\right), 0.85\left(3 \mathrm{H}, \mathrm{s}, \mathrm{CH}_{3}\right)$, $0.78\left(3 \mathrm{H}, \mathrm{s}, \mathrm{CH}_{3}\right) ;{ }^{13} \mathrm{C}$ NMR $\left(150 \mathrm{MHz}, \mathrm{CDCl}_{3}\right): \delta 156.0$ $(\mathrm{O}-\mathrm{C}=\mathrm{O}), 150.1$ (C-20), 109.9 (C-29), 79.0 (C-3), 69.6, 66.4 (C-28), 55.3, 50.4, 48.8, 47.7, 46.6, 42.7, 40.9, 38.9, $38.7,37.6,37.1,34.4,34.2,29.6,29.5,28.0,27.4,27.0$, 25.2, 22.0, 20.8, 19.1, 18.3, 16.1, 16.0, 15.3, 14.8, 10.2; EIMS $m / z 528[\mathrm{M}]^{+}(19), 189$ (100).

28-O-Allyloxycarbonylbetulin (11) Yield 66\%; m.p. 91-94 ${ }^{\circ} \mathrm{C} ; R_{\mathrm{f}} 0.47$ (chloroform/ethanol, 40:1, v/v); IR (KBr) $\nu{ }_{\max } 3405,2962,1737,1457,1270 \mathrm{~cm}^{-1} ;{ }^{1} \mathrm{H}$ NMR (600 $\left.\mathrm{MHz}, \mathrm{CDCl}_{3}\right): \delta 5.98\left(1 \mathrm{H}, \mathrm{m}, \mathrm{CH}=\mathrm{CH}_{2}\right), 5.38(1 \mathrm{H}, \mathrm{m}$, $\left.\mathrm{CH}=\underline{\mathrm{CH}_{2}}\right), 5.31\left(1 \mathrm{H}, \mathrm{m}, \mathrm{CH}=\underline{\mathrm{CH}_{2}}\right), 4.71(1 \mathrm{H}, \mathrm{s}, \mathrm{H}-29)$, $4.66\left(2 \mathrm{H}, \mathrm{m}, \mathrm{OCH}_{2}\right), 4.61(1 \mathrm{H}, \mathrm{s}, \mathrm{H}-29), 4.38(1 \mathrm{H}, \mathrm{d}, J=$ $10.8 \mathrm{~Hz}, \mathrm{H}-28), 3.95(1 \mathrm{H}, \mathrm{d}, J=10.8 \mathrm{~Hz}, \mathrm{H}-28), 3.21(1 \mathrm{H}$, $\mathrm{m}, \mathrm{H}-3), 2.46(1 \mathrm{H}, \mathrm{m}, \mathrm{H}-19), 1.68\left(3 \mathrm{H}, \mathrm{s}, \mathrm{CH}_{3}\right), 1.06(3 \mathrm{H}, \mathrm{s}$, $\left.\mathrm{CH}_{3}\right), 1.00\left(3 \mathrm{H}, \mathrm{s}, \mathrm{CH}_{3}\right), 0.99\left(3 \mathrm{H}, \mathrm{s}, \mathrm{CH}_{3}\right), 0.84(3 \mathrm{H}, \mathrm{s}$, $\left.\mathrm{CH}_{3}\right), 0.78\left(3 \mathrm{H}, \mathrm{s}, \mathrm{CH}_{3}\right) ;{ }^{13} \mathrm{C} \mathrm{NMR}\left(150 \mathrm{MHz}, \mathrm{CDCl}_{3}\right): \delta$ $155.6(\mathrm{O}-\mathrm{C}=\mathrm{O}), 150.1(\mathrm{C}-20), 131.7,118.9,109.9(\mathrm{C}-29)$, 78.9 (C-3), 68.5, 66.7 (C-28), 55.3, 50.4, 48.8, 47.7, 46.6, $42.7,40.9,38.9,38.7,37.6,37.2,34.4,34.2,29.7,29.6$, 28.0, 27.4, 27.0, 25.2, 20.8, 19.1, 18.3, 16.1, 16.0, 15.4, 14.8; EIMS m/z $496[\mathrm{M}]^{+}$(14), 189 (100).

\section{General procedure for the synthesis of derivatives 15-26}

To a solution of the appropriate monoester 3-14 (1 mmol) in dry dichloromethane $(12 \mathrm{~mL})$ was added pyridinium chloroformate $(0.53 \mathrm{~g}, 2.48 \mathrm{mmol})$. The reaction was stirred at room temperature for $2 \mathrm{~h}$ and then diluted with ether (16 $\mathrm{mL}$ ) and still was stirred for $10 \mathrm{~min}$. The reaction mixture was filtered off through a layer of silica gel and washed with ether $(5 \mathrm{~mL})$. The filtrate was concentrated under reduced pressure and the residue was purified by silica gel column chromatography (chloroform/ethanol 40:1, v/v).

28-O-Propanoylbetulone (15) Yield 82\%; m.p. $65-67^{\circ} \mathrm{C}$; $R_{\mathrm{f}} 0.64$ (chloroform/ethanol, 40:1, v/v); IR (KBr) $\nu$ max 2945, 1733, 1705, 1462, $1187 \mathrm{~cm}^{-1} ;{ }^{1} \mathrm{H}$ NMR $\left(600 \mathrm{MHz}, \mathrm{CDCl}_{3}\right): \delta$ $4.72(1 \mathrm{H}, \mathrm{s}, \mathrm{H}-29), 4.62(1 \mathrm{H}, \mathrm{s}, \mathrm{H}-29), 4.30(1 \mathrm{H}, \mathrm{d}, J=10.8$ $\mathrm{Hz}, \mathrm{H}-28), 3.86(1 \mathrm{H}, \mathrm{d}, J=10.8 \mathrm{~Hz}, \mathrm{H}-28), 2.49(1 \mathrm{H}, \mathrm{m}, \mathrm{H}-$ 19), $2.37\left(2 \mathrm{H}, \mathrm{q}, J=7.2 \mathrm{~Hz}, \mathrm{CH}_{2} \mathrm{CH}_{3}\right), 1.69\left(3 \mathrm{H}, \mathrm{s}, \mathrm{CH}_{3}\right), 1.18$ $\left(3 \mathrm{H}, \mathrm{t}, J=7.2 \mathrm{~Hz}, \mathrm{CH}_{2} \mathrm{CH}_{3}\right), 1.10\left(3 \mathrm{H}, \mathrm{s}, \mathrm{CH}_{3}\right), 1.09(3 \mathrm{H}, \mathrm{s}$, $\left.\mathrm{CH}_{3}\right), 1.05\left(3 \mathrm{H}, \mathrm{s}, \mathrm{CH}_{3}\right), 1.01\left(3 \mathrm{H}, \mathrm{s}, \mathrm{CH}_{3}\right), 0.96\left(3 \mathrm{H}, \mathrm{s}, \mathrm{CH}_{3}\right)$; ${ }^{13} \mathrm{C}$ NMR $\left(150 \mathrm{MHz}, \mathrm{CDCl}_{3}\right): \delta 218.0(\mathrm{C}=\mathrm{O}), 174.9$ $(\mathrm{O}-\mathrm{C}=\mathrm{O}), 150.1$ (C-20), 109.9 (C-29), 62.5 (C-28), 55.0, 49.8, 48.8, 47.7, 47.4, 46.4, 42.8, 40.8, 39.6, 37.7, 36.9, 34.6, 34.2, 33.5, 29.8, 29.6, 27.7, 27.1, 26.6, 25.2, 21.3, 21.1, 19.6, 19.2, 15.9, 15.8, 14.7, 9.2; EIMS m/z $526[\mathrm{M}]^{+}$(23), 189 (100). 
28-O-(2-Propenoyl)betulone (16) Yield 62\%; m.p. 69-71 ${ }^{\circ} \mathrm{C} ; R_{\mathrm{f}} 0.62$ (chloroform/ethanol, 40:1, v/v); IR (KBr) $\nu \max 2962,1723,1706,1456,1261 \mathrm{~cm}^{-1} ;{ }^{1} \mathrm{H}$ NMR $(600$ $\left.\mathrm{MHz}, \mathrm{CDCl}_{3}\right): \delta 6.34\left(1 \mathrm{H}, \mathrm{m}, \mathrm{CH}=\mathrm{CH}_{2}\right), 6.06(1 \mathrm{H}, \mathrm{m}$, $\left.\mathrm{CH}=\mathrm{CH}_{2}\right), 5.75\left(1 \mathrm{H}, \mathrm{m}, \mathrm{CH}=\mathrm{CH}_{2}\right), 4.63(1 \mathrm{H}, \mathrm{s}, \mathrm{H}-29)$, 4.53 (1H, s, H-29), 4.30 (1H, d, J=10.8 Hz, H-28), 3.86 $(1 \mathrm{H}, \mathrm{d}, J=10.8 \mathrm{~Hz}, \mathrm{H}-28), 2.40(1 \mathrm{H}, \mathrm{m}, \mathrm{H}-19), 1.65(3 \mathrm{H}, \mathrm{s}$, $\left.\mathrm{CH}_{3}\right), 1.01\left(3 \mathrm{H}, \mathrm{s}, \mathrm{CH}_{3}\right), 1.00\left(3 \mathrm{H}, \mathrm{s}, \mathrm{CH}_{3}\right), 0.96(3 \mathrm{H}, \mathrm{s}$, $\left.\mathrm{CH}_{3}\right), 0.92\left(3 \mathrm{H}, \mathrm{s}, \mathrm{CH}_{3}\right), 0.87\left(3 \mathrm{H}, \mathrm{s}, \mathrm{CH}_{3}\right) ;{ }^{13} \mathrm{C}$ NMR $(150$ $\left.\mathrm{MHz}_{,} \mathrm{CDCl}_{3}\right): \delta 217.0(\mathrm{C}=\mathrm{O}), 165.6(\mathrm{O}-\mathrm{C}=\mathrm{O}), 149.0(\mathrm{C}-$ 20), 129.5, 127.6, 108.9 (C-29), 61.8 (C-28), 53.9, 48.7, $47.7,46.7,46.3,45.5,41.8,39.8,38.6,36.7,35.9,33.5$, $33.1,32.4,28.7,28.6,26.1,25.5,24.2,20.3,20.0,18.6$, 18.1, 14.9, 14.8, 13.7; EIMS m/z 495 [M] $]^{+}$(27), 203 (100).

28-O-Propynoylbetulone (17) Yield $78 \%$; m.p. 93-96 ${ }^{\circ} \mathrm{C}$; $R_{\mathrm{f}} 0.65$ (chloroform/ethanol, 40:1, v/v); IR (KBr) $\nu \max _{\text {max }} 3301$, 2948, 2117, 1712, 1708, $1225 \mathrm{~cm}^{-1}$; ${ }^{1} \mathrm{H}$ NMR $(600 \mathrm{MHz}$, $\left.\mathrm{CDCl}_{3}\right): \delta 4.69(1 \mathrm{H}, \mathrm{s}, \mathrm{H}-29), 4.60(1 \mathrm{H}, \mathrm{s}, \mathrm{H}-29), 4.38(1 \mathrm{H}, \mathrm{d}$, $J=10.8 \mathrm{~Hz}, \mathrm{H}-28), 3.99$ (1H, d, $J=10.8 \mathrm{~Hz}, \mathrm{H}-28), 2.89(1 \mathrm{H}$, $\mathrm{s}, \mathrm{C} \equiv \underline{\mathrm{CH}}), 2.48(1 \mathrm{H}, \mathrm{m}, \mathrm{H}-19), 1.68\left(3 \mathrm{H}, \mathrm{s}, \mathrm{CH}_{3}\right), 1.07(3 \mathrm{H}, \mathrm{s}$, $\left.\mathrm{CH}_{3}\right), 1.06\left(3 \mathrm{H}, \mathrm{s}, \mathrm{CH}_{3}\right), 1.03\left(3 \mathrm{H}, \mathrm{s}, \mathrm{CH}_{3}\right), 0.88\left(3 \mathrm{H}, \mathrm{s}, \mathrm{CH}_{3}\right)$, $0.80\left(3 \mathrm{H}, \mathrm{s}, \mathrm{CH}_{3}\right) ;{ }^{13} \mathrm{C} \mathrm{NMR}\left(150 \mathrm{MHz}, \mathrm{CDCl}_{3}\right): \delta 217.9$ $(\mathrm{C}=\mathrm{O}), 153.2(\mathrm{O}-\mathrm{C}=\mathrm{O}), 149.8$ (C-20), 110.0 (C-29), 74.8, 74.6, 64.8 (C-28), 55.0, 49.7, 48.8, 47.6, 47.3, 46.4, 42.8, 40.8, $39.6,37.8,36.9,34.4,34.1,33.5,29.6,29.5,27.0,26.6,25.2$, 21.3, 21.0, 19.6, 19.1, 15.9, 15.8, 14.7; EIMS m/z $492[\mathrm{M}]^{+}$ (28), 203 (100).

28-O-(3-Cyclopropyl-2-propynoyl)betulone (18) Yield $83 \%$; m.p. 93-97 ${ }^{\circ} \mathrm{C} ; R_{\mathrm{f}} 0.65$ (chloroform/ethanol, 40:1, v/v); $\mathrm{IR}(\mathrm{KBr}) \nu_{\max } 2947,2232,1711,1705,1457,1249 \mathrm{~cm}^{-1} ;{ }^{1} \mathrm{H}$ NMR (600 MHz, $\left.\mathrm{CDCl}_{3}\right): \delta 4.71(1 \mathrm{H}, \mathrm{s}, \mathrm{H}-29), 4.62(1 \mathrm{H}, \mathrm{s}$, H-29), 4.35 (1H, d, $J=10.8 \mathrm{~Hz}, \mathrm{H}-28), 3.96(1 \mathrm{H}, \mathrm{d}, J=10.8$ Hz, H-28), 2.43 (1H, m, H-19), 1.68 (3H, s, $\left.\mathrm{CH}_{3}\right), 1.09$ (3H, $\left.\mathrm{s}, \mathrm{CH}_{3}\right), 1.08\left(3 \mathrm{H}, \mathrm{s}, \mathrm{CH}_{3}\right), 1.05\left(3 \mathrm{H}, \mathrm{s}, \mathrm{CH}_{3}\right), 1.00(3 \mathrm{H}, \mathrm{s}$, $\left.\mathrm{CH}_{3}\right), 0.97-0.96\left(5 \mathrm{H}, \mathrm{m}, \mathrm{CH}, \mathrm{CH}_{2}\right), 0.95\left(3 \mathrm{H}, \mathrm{s}, \mathrm{CH}_{3}\right) ;{ }^{13} \mathrm{C}$ $\mathrm{NMR}\left(150 \mathrm{MHz}, \mathrm{CDCl}_{3}\right): \delta 218.5(\mathrm{C}=\mathrm{O}), 155.0(\mathrm{O}-\mathrm{C}=\mathrm{O})$, 150.5 (C-20), 110.5 (C-29), 93.9, 69.1, 64.6 (C-28), 55.5, 50.3, 49.3, 48.2, 47.9, 46.9, 43.3, 41.4, 40.2, 38.3, 37.4, 35.1, 34.7, 34.0, 30.2, 30.1, 27.6, 27.1, 25.8, 21.9, 21.6, 20.2, 19.7, 16.5, 16.4, 15.2, 9.4 1.3, -0.4; EIMS m/z $533[\mathrm{M}]^{+}(14), 93$ (100).

28-O-Phenylpropynoylbetulone (19) Yield $82 \%$; m.p. 82-85 ${ }^{\circ} \mathrm{C} ; R_{\mathrm{f}} 0.64$ (chloroform/ethanol, 40:1, v/v); IR (KBr) $\nu_{\max } 2945,2223,1722,1707,1457,1187 \mathrm{~cm}^{-1} ;{ }^{1} \mathrm{H}$ NMR $\left(600 \mathrm{MHz} \mathrm{CDCl}_{3}\right): \delta 7.60-7.37(5 \mathrm{H}, \mathrm{m}, \mathrm{Ar}-\mathrm{H}), 4.71(1 \mathrm{H}, \mathrm{s}$, H-29), 4.61 (1H, s, H-29), 4.43 (1H, d, J=10.8 Hz, H-28), 4.04 (1H, d, $J=10.8 \mathrm{~Hz}, \mathrm{H}-28), 2.41$ (1H, m, H-19), 1.69 $\left(3 \mathrm{H}, \mathrm{s}, \mathrm{CH}_{3}\right), 1.09\left(3 \mathrm{H}, \mathrm{s}, \mathrm{CH}_{3}\right), 1.07\left(3 \mathrm{H}, \mathrm{s}, \mathrm{CH}_{3}\right), 1.03$ $\left(3 \mathrm{H}, \mathrm{s}, \mathrm{CH}_{3}\right), 1.00\left(3 \mathrm{H}, \mathrm{s}, \mathrm{CH}_{3}\right), 0.94\left(3 \mathrm{H}, \mathrm{s}, \mathrm{CH}_{3}\right) ;{ }^{13} \mathrm{C}$ $\mathrm{NMR}\left(150 \mathrm{MHz}, \mathrm{CDCl}_{3}\right): \delta 218.0(\mathrm{C}=\mathrm{O}), 154.7(\mathrm{O}-\mathrm{C}=\mathrm{O})$, 149.9 (C-20), 132.9, 130.6, 128.5, 110.0 (C-29), 86.3, 80.7, 64.5 (C-28), 54.9, 49.7, 48.8, 47.6, 47.3, 46.4, 42.8, 40.8, $39.6,37.8,36.8,34.5,34.1,33.5,29.6,29.5,27.0,26.6$,
25.2, 21.3, 21.0, 19.6, 19.1, 15.9, 15.8, 14.7; EIMS m/z 569 $[\mathrm{M}]^{+}(16), 129$ (100).

28-O-(2-Butenoyl)betulone (20) Yield 81\%; m.p. 129-131 ${ }^{\circ} \mathrm{C} ; \mathrm{R}_{\mathrm{f}} 0.63$ (chloroform/ethanol, 40:1, v/v); IR $(\mathrm{KBr}) \nu_{\max } 2944,1719,1708,1457,1179 \mathrm{~cm}^{-1} ;{ }^{1} \mathrm{H}$ NMR $\left(600 \mathrm{MHz}, \mathrm{CDCl}_{3}\right): \delta 7.00\left(1 \mathrm{H}, \mathrm{m}, \mathrm{CH}=\mathrm{CHCH}_{3}\right), 5.89(1 \mathrm{H}$, $\left.\mathrm{m}, \underline{\mathrm{CH}}=\mathrm{CHCH}_{3}\right), 4.72(1 \mathrm{H}, \mathrm{s}, \mathrm{H}-29), \overline{4.62}(1 \mathrm{H}, \mathrm{s}, \mathrm{H}-29)$, $4.34(1 \mathrm{H}, \mathrm{d}, J=10.8 \mathrm{~Hz}, \mathrm{H}-28), 3.93(1 \mathrm{H}, \mathrm{d}, J=10.8 \mathrm{~Hz}$, $\mathrm{H}-28), 2.42(1 \mathrm{H}, \mathrm{m}, \mathrm{H}-19), 1.92\left(3 \mathrm{H}, \mathrm{m}, \mathrm{CH}=\mathrm{CHCH}_{3}\right)$, $1.69\left(3 \mathrm{H}, \mathrm{s}, \mathrm{CH}_{3}\right), 1.10\left(3 \mathrm{H}, \mathrm{s}, \mathrm{CH}_{3}\right), 1.09\left(3 \mathrm{H}, \mathrm{s}, \overline{\mathrm{CH}_{3}}\right)$, $1.07\left(3 \mathrm{H}, \mathrm{s}, \mathrm{CH}_{3}\right), 1.01\left(3 \mathrm{H}, \mathrm{s}, \mathrm{CH}_{3}\right), 0.96\left(3 \mathrm{H}, \mathrm{s}, \mathrm{CH}_{3}\right) ;{ }^{13} \mathrm{C}$ NMR (150 MHz, $\left.\mathrm{CDCl}_{3}\right): \delta 218.1(\mathrm{C}=\mathrm{O}), 167.0(\mathrm{O}-\mathrm{C}=\mathrm{O})$, 150.1 (C-20), 144.5, 122.8, 109.9 (C-29), 62.4 (C-28), 55.0, $49.8,48.8,47.7,47.4,46.5,42.8,40.8,39.6,37.7,36.8$, $34.6,34.2,33.5,29.8,29.6,27.1,26.6,25.2,21.3,21.1$, 19.6, 18.0, 15.9, 15.8, 14.7, 3.6; EIMS m/z $510[\mathrm{M}]^{+}(14)$, 189 (100).

28-O-(2-Butynoyl)betulone (21) Yield 78\%; m.p. 92-94 ${ }^{\circ} \mathrm{C} ; R_{\mathrm{f}} 0.66$ (chloroform/ethanol, 40:1, v/v); IR (KBr) $\nu_{\max } 2960,2245,1742,1707,1458,1260 \mathrm{~cm}^{-1} ;{ }^{1} \mathrm{H}$ NMR $\left(600 \mathrm{MHz}, \mathrm{CDCl}_{3}\right): \delta 4.69(1 \mathrm{H}, \mathrm{s}, \mathrm{H}-29), 4.59(1 \mathrm{H}, \mathrm{s}, \mathrm{H}-$ 29), 4.34 (1H, d, $J=10.8 \mathrm{~Hz}, \mathrm{H}-28), 3.94$ (1H, d, $J=10.8$ Hz, H-28), 2.44 (1H, m, H-19), 1.99 (3H, s, C $\left.\equiv \mathrm{CCH}_{3}\right), 1.68$ $\left(3 \mathrm{H}, \mathrm{s}, \mathrm{CH}_{3}\right), 1.07\left(3 \mathrm{H}, \mathrm{s}, \mathrm{CH}_{3}\right), 1.06\left(3 \mathrm{H}, \mathrm{s}, \mathrm{CH}_{3}\right), 1.03$ $\left(3 \mathrm{H}, \mathrm{s}, \mathrm{CH}_{3}\right), 0.99\left(3 \mathrm{H}, \mathrm{s}, \mathrm{CH}_{3}\right), 0.93\left(3 \mathrm{H}, \mathrm{s}, \mathrm{CH}_{3}\right) ;{ }^{13} \mathrm{C}$ NMR (150 MHz, $\left.\mathrm{CDCl}_{3}\right): \delta 218.0(\mathrm{C}=\mathrm{O}), 154.4(\mathrm{O}-\mathrm{C}=\mathrm{O})$, 149.9 (C-20), 110.0 (C-29), 85.6, 72.5, 64.2 (C-28), 55.0, $49.7,48.8,47.6,47.3,46.4,42.7,40.8,39.6,37.7,36.8$, $34.5,34.1,33.5,29.6,29.5,27.0,26.6,25.2,21.3,21.0$, 19.6, 19.1, 15.9, 15.8, 14.7, 3.8; EIMS m/z $507[\mathrm{M}]^{+}(29)$, 422 (100).

28-O-Propoxycarbonylbetulone (22) Yield $78 \%$; m.p. $76-78^{\circ} \mathrm{C} ; R_{\mathrm{f}} 0.63$ (chloroform/ethanol, 40:1, v/v); IR (KBr) $\nu_{\max } 2963,1741,1700,1458,1256 \mathrm{~cm}^{-1} ;{ }^{1} \mathrm{H}$ NMR $(600$ $\left.\mathrm{MHz}, \mathrm{CDCl}_{3}\right): \delta 4.72(1 \mathrm{H}, \mathrm{s}, \mathrm{H}-29), 4.62(1 \mathrm{H}, \mathrm{s}, \mathrm{H}-29)$, $4.37(1 \mathrm{H}, \mathrm{d}, J=10.8 \mathrm{~Hz}, \mathrm{H}-28), 4.13(2 \mathrm{H}, \mathrm{t}, J=6.6 \mathrm{~Hz}$, $\left.\mathrm{OCH}_{2}\right), 3.95(1 \mathrm{H}, \mathrm{d}, J=10.8 \mathrm{~Hz}, \mathrm{H}-28), 2.45(1 \mathrm{H}, \mathrm{m}, \mathrm{H}-$ 19), $1.74\left(2 \mathrm{H}, \mathrm{m}, \mathrm{CH}_{2} \mathrm{CH}_{3}\right), 1.68\left(3 \mathrm{H}, \mathrm{s}, \mathrm{CH}_{3}\right), 1.10(3 \mathrm{H}, \mathrm{s}$, $\left.\mathrm{CH}_{3}\right), 1.09\left(3 \mathrm{H}, \mathrm{s}, \mathrm{CH}_{3}\right), 1.05\left(3 \mathrm{H}, \mathrm{s}, \mathrm{CH}_{3}\right), 1.01(3 \mathrm{H}, \mathrm{s}$, $\left.\mathrm{CH}_{3}\right), 0.99$ (3H, t, J=7.2 Hz, $\left.\mathrm{CH}_{2} \mathrm{CH}_{3}\right), 0.96$ (s, $\left.\mathrm{CH}_{3}, 3 \mathrm{H}\right)$; ${ }^{13} \mathrm{C}$ NMR $\left(150 \mathrm{MHz}, \mathrm{CDCl}_{3}\right): \bar{\delta} 218.0 \quad(\mathrm{C}=\mathrm{O}), 156.0$ $(\mathrm{O}-\mathrm{C}=\mathrm{O}), 150.0$ (C-20), 109.9 (C-29), 69.6, 66.4 (C-28), 55.0, 49.7, 48.8, 47.7, 46.6, 42.8, 40.8, 39.6, 37.7, 36.9, $34.4,34.2,33.5,29.6,29.5,27.1,26.6,25.6,25.2,22.1$, 21.3, 21.1, 19.6, 19.1, 15.9, 15.8, 14.7, 10.2; EIMS m/z 526 $[\mathrm{M}]^{+}(15), 422$ (100).

28-O-Allyloxycarbonylbetulone (23) Yield 72\%; m.p. 123-125 ${ }^{\circ} \mathrm{C} ; R_{\mathrm{f}} 0.66$ (chloroform/ethanol, 40:1, v/v); IR (KBr) $\nu{ }_{\max } 2945,1741,1710,1457,1248 \mathrm{~cm}^{-1} ;{ }^{1} \mathrm{H}$ NMR $\left(600 \mathrm{MHz} \mathrm{CDCl}_{3}\right): \delta 5.98\left(1 \mathrm{H}, \mathrm{m}, \mathrm{CH}=\mathrm{CH}_{2}\right), 5.40(1 \mathrm{H}$, $\left.\mathrm{m}, \mathrm{CH}=\underline{\mathrm{CH}_{2}}\right), 5.31\left(1 \mathrm{H}, \mathrm{m}, \mathrm{CH}=\underline{\mathrm{CH}_{2}}\right), 4.72(1 \mathrm{H}, \mathrm{s}, \mathrm{H}-29)$, $4.66\left(2 \mathrm{H}, \mathrm{m}, \mathrm{OCH}_{2}\right), 4.62(1 \mathrm{H}, \mathrm{s}, \mathrm{H}-29), 4.38(1 \mathrm{H}, \mathrm{d}, J=$ $10.8 \mathrm{~Hz}, \mathrm{H}-28), 3.96$ (1H, d, $J=10.8 \mathrm{~Hz}, \mathrm{H}-28), 2.44(1 \mathrm{H}$, 
m, H-19), $1.68\left(3 \mathrm{H}, \mathrm{s}, \mathrm{CH}_{3}\right), 1.10\left(3 \mathrm{H}, \mathrm{s}, \mathrm{CH}_{3}\right), 1.09(3 \mathrm{H}, \mathrm{s}$, $\left.\mathrm{CH}_{3}\right), 1.08\left(3 \mathrm{H}, \mathrm{s}, \mathrm{CH}_{3}\right), 1.05\left(3 \mathrm{H}, \mathrm{s}, \mathrm{CH}_{3}\right), 0.96(3 \mathrm{H}, \mathrm{s}$, $\left.\mathrm{CH}_{3}\right) ;{ }^{13} \mathrm{C}$ NMR $\left(150 \mathrm{MHz}, \mathrm{CDCl}_{3}\right): \delta 218.0(\mathrm{C}=\mathrm{O}), 155.6$ $(\mathrm{O}-\mathrm{C}=\mathrm{O}), 150.0(\mathrm{C}-20), 131.7,119.0,109.9(\mathrm{C}-29), 68.5$, 66.6 (C-28), 55.0, 53.4, 49.7, 48.8, 47.7, 47.4, 46.6, 42.8, $40.8,39.6,37.7,36.9,34.4,34.2,33.5,29.6,29.5,27.0$, 26.6, 25.2, 21.3, 21.1, 19.6, 15.9, 15.8, 14.7; EIMS m/z 524 $[\mathrm{M}]^{+}(19), 422(100)$.

28-O-Propargyloxycarbonylbetulone (24) Yield 73\%; m.p. $173-175^{\circ} \mathrm{C} ; R_{\mathrm{f}} 0.64$ (chloroform/ethanol, $40: 1$, v/v); IR (KBr) $\nu$ max 3245, 2944, 2131, 1721, 1706, 1452, 1269 $\mathrm{cm}^{-1} ;{ }^{1} \mathrm{H}$ NMR $\left(600 \mathrm{MHz}, \mathrm{CDCl}_{3}\right): \delta 4.74(2 \mathrm{H}, \mathrm{d}, J=2.4$ $\left.\mathrm{Hz}, \mathrm{OCH}_{2}\right), 4.69(1 \mathrm{H}, \mathrm{s}, \mathrm{H}-29), 4.60(1 \mathrm{H}, \mathrm{s}, \mathrm{H}-29), 4.38$ $(1 \mathrm{H}, \mathrm{d}, J=10.8 \mathrm{~Hz}, \mathrm{H}-28), 3.96(1 \mathrm{H}, \mathrm{d}, J=10.8 \mathrm{~Hz}, \mathrm{H}-28)$, $2.54(1 \mathrm{H}, \mathrm{t}, J=2.4 \mathrm{~Hz}, \mathrm{C} \equiv \mathrm{CH}), 2.41(1 \mathrm{H}, \mathrm{m}, \mathrm{H}-19), 1.68$ $\left(3 \mathrm{H}, \mathrm{s}, \mathrm{CH}_{3}\right), 1.09\left(3 \mathrm{H}, \mathrm{s}, \mathrm{CH}_{3}\right), 1.07\left(3 \mathrm{H}, \mathrm{s}, \mathrm{CH}_{3}\right), 1.03$ $\left(3 \mathrm{H}, \mathrm{s}, \mathrm{CH}_{3}\right), 0.99\left(3 \mathrm{H}, \mathrm{s}, \mathrm{CH}_{3}\right), 0.93\left(3 \mathrm{H}, \mathrm{s}, \mathrm{CH}_{3}\right) ;{ }^{13} \mathrm{C}$ NMR (150 MHz, $\left.\mathrm{CDCl}_{3}\right): \delta 218.0(\mathrm{C}=\mathrm{O}), 155.1(\mathrm{O}-\mathrm{C}=\mathrm{O})$, 149.9 (C-20), 110.0 (C-29), 76.8, 75.6, 75.4, 67.2 (C-28), 55.2, 54.9, 49.7, 48.7, 47.6, 46.5, 42.8, 40.8, 39.6, 37.7, $36.8,34.3,34.1,33.4,29.5,29.4,26.9,26.6,25.2,21.3$, 21.0, 19.6, 19.1, 15.9, 15.8, 14.7; EIMS $m / z 523[\mathrm{M}]^{+}(24)$, 189 (100).

28-O-(3-Butynyloxycarbonyl)betulone (25) Yield 77\%; m.p. $81-84{ }^{\circ} \mathrm{C} ; R_{\mathrm{f}} 0.63$ (chloroform/ethanol, 40:1, v/v); IR (KBr) $\nu \max _{\text {ax }} 3310,2948,2360,1744,1705,1458,1248$ $\mathrm{cm}^{-1} ;{ }^{1} \mathrm{H}$ NMR $\left(600 \mathrm{MHz}, \mathrm{CDCl}_{3}\right): \delta 4.69(1 \mathrm{H}, \mathrm{s}, \mathrm{H}-29)$, $4.59(1 \mathrm{H}, \mathrm{s}, \mathrm{H}-29), 4.36(1 \mathrm{H}, \mathrm{d}, J=10.8 \mathrm{~Hz}, \mathrm{H}-28), 4.25$ $\left(2 \mathrm{H}, \mathrm{t}, J=7.2 \mathrm{~Hz}, \underline{\mathrm{OCH}_{2}}\right), 3.94(1 \mathrm{H}, \mathrm{d}, J=10.8 \mathrm{~Hz}, \mathrm{H}-28)$, $2.60\left(2 \mathrm{H}, \mathrm{m}, \mathrm{OCH}_{2} \mathrm{CH}_{2}\right), 2.41(1 \mathrm{H}, \mathrm{m}, \mathrm{H}-19), 2.03(1 \mathrm{H}, \mathrm{t}, J$ $=2.4 \mathrm{~Hz}, \mathrm{C} \equiv \mathrm{CH}), 1.68\left(3 \mathrm{H}, \mathrm{s}, \mathrm{CH}_{3}\right), 1.08\left(3 \mathrm{H}, \mathrm{s}, \mathrm{CH}_{3}\right)$, $1.07\left(3 \mathrm{H}, \mathrm{s}, \overline{\mathrm{CH}}_{3}\right), 1.03\left(3 \mathrm{H}, \mathrm{s}, \mathrm{CH}_{3}\right), 0.98\left(3 \mathrm{H}, \mathrm{s}, \mathrm{CH}_{3}\right)$, $0.93\left(3 \mathrm{H}, \mathrm{s}, \mathrm{CH}_{3}\right) ;{ }^{13} \mathrm{C}$ NMR $\left(150 \mathrm{MHz}, \mathrm{CDCl}_{3}\right): \delta 218.2$ $(\mathrm{C}=\mathrm{O}), 155.5(\mathrm{O}-\mathrm{C}=\mathrm{O}), 149.9(\mathrm{C}-20), 110.0(\mathrm{C}-29), 79.4$, 76.8, 70.2, 66.7 (C-28), 65.3, 54.9, 49.6, 48.7, 47.6, 47.3, $46.5,42.7,40.8,39.6,37.6,36.8,34.3,34.1,33.4,29.5$, 29.4, 26.9, 26.5, 25.1, 21.2, 21.0, 19.6, 19.0, 15.9, 15.8, 14.6; EIMS m/z 537 [M] ${ }^{+}(14), 189$ (100).

28-O-(2-Butynyloxycarbonyl)betulone (26) Yield 75\%; m.p. $150-152{ }^{\circ} \mathrm{C} ; R_{\mathrm{f}} 0.59$ (chloroform/ethanol, $40: 1, \mathrm{v} / \mathrm{v}$ ); IR (KBr) $\nu \max 2956,2231,1742,1704,1458,1255 \mathrm{~cm}^{-1}$; ${ }^{1} \mathrm{H}$ NMR $\left(600 \mathrm{MHz}, \mathrm{CDCl}_{3}\right): \delta 4.71(2 \mathrm{H}, \mathrm{q}, J=2.4 \mathrm{~Hz}$, $\left.\mathrm{OCH}_{2}\right), 4.69(1 \mathrm{H}, \mathrm{s}, \mathrm{H}-29), 4.59(1 \mathrm{H}, \mathrm{s}, \mathrm{H}-29), 4.36(1 \mathrm{H}, \mathrm{d}$, $J=10.8 \mathrm{~Hz}, \mathrm{H}-28), 3.93(1 \mathrm{H}, \mathrm{d}, J=10.8 \mathrm{~Hz}, \mathrm{H}-28), 2.42$ $(1 \mathrm{H}, \mathrm{m}, \mathrm{H}-19), 1.87\left(3 \mathrm{H}, \mathrm{t}, J=2.4 \mathrm{~Hz}, \mathrm{C} \equiv \mathrm{CCH}_{3}\right), 1.68(3 \mathrm{H}$, $\left.\mathrm{s}, \mathrm{CH}_{3}\right), 1.08\left(3 \mathrm{H}, \mathrm{s}, \mathrm{CH}_{3}\right), 1.07\left(3 \mathrm{H}, \mathrm{s}, \mathrm{CH}_{3}\right), 1.03(3 \mathrm{H}, \mathrm{s}$, $\left.\mathrm{CH}_{3}\right), 0.98\left(3 \mathrm{H}, \mathrm{s}, \mathrm{CH}_{3}\right), 0.93\left(3 \mathrm{H}, \mathrm{s}, \mathrm{CH}_{3}\right) ;{ }^{13} \mathrm{C} \mathrm{NMR}(150$ $\left.\mathrm{MHz}, \mathrm{CDCl}_{3}\right): \delta 218.2(\mathrm{C}=\mathrm{O}), 155.2(\mathrm{O}-\mathrm{C}=\mathrm{O}), 149.9$ (C-20), 110.0 (C-29), 84.1, 76.7, 72.6, 66.9 (C-28), 56.1, 54.9, 49.6, 48.7, 47.6, 47.3, 46.5, 42.7, 40.8, 39.6, 37.7, $36.8,34.3,33.4,29.5,29.4,26.9,26.5,25.1,21.2,21.0$, 19.6, 19.1, 15.9, 15.8, 14.6, 3.7; EIMS m/z $537[\mathrm{M}]^{+}(14)$, 189 (100).

\section{Antiproliferative Assay in vitro}

\section{Cells}

The targeted compounds were evaluated for their cytotoxicity towards the cancer cell lines including T47D (human breast cancer), CCRF/CEM (human leukemia), SW707 (human colorectal), HL-60 (human promyelocytic leukemia), P388 (mouse leukemia), as well as BALB3T3 normal mouse fibroblasts cell line. The tested cell lines were obtained from the American Type Culture Collection (Rockville, Maryland, USA) and maintained at the Cell Culture Collection of the Institute of Immunology and Experimental Therapy (Wrocław, Poland). The cells were seeded in 96-well plates (Sarstedt, USA) at a density of $10^{4}$ cells per well in $100 \mu \mathrm{L}$ of culture medium overnight. The cancer cell lines CCRF/CEM (human leukemia) and P388 (mouse leukemia) were cultured in RPMI 1640 medium (Gibco, Scotland, UK) supplemented with $2 \mathrm{mM}$ glutamine (Sigma-Aldrich, Chemie GmbH, Steinheim, Germany) and $10 \%$ fetal calf serum FBS (Sigma-Aldrich, Chemie GmbH, Steinheim, Germany). The cancer cell lines SW707 (human colorectal), T47D (human breast cancer) and HL-60 (human promyelocytic leukemia) were cultured in mixture of RPMI 1640 and Opti-MEM (1:1) medium (both from Gibco, Scotland, UK) supplemented with $2 \mathrm{mM}$ glutamine (SigmaAldrich, Chemie $\mathrm{GmbH}$, Steinheim, Germany) and $5 \%$ or $20 \%$ fetal calf serum FBS (Sigma-Aldrich, Chemie GmbH, Steinheim, Germany). The normal mouse fibroblasts BALB3T3 was cultured in Dulbecco's modified Eagle's medium (Sigma-Aldrich, Chemie GmbH, Steinheim, Germany) supplemented with $2 \mathrm{mM}$ glutamine (Sigma-Aldrich, Chemie GmbH, Steinheim, Germany) and $10 \%$ fetal calf serum FBS (Sigma-Aldrich, Chemie GmbH, Steinheim, Germany). The all culture media were supplemented with streptomycin $(100 \mu \mathrm{g} / \mathrm{mL})$ and penicillin $(100 \mathrm{U} / \mathrm{mL})$ (both antibiotics from Polfa, Tarchomin, Poland). The cell cultures were maintained at $37{ }^{\circ} \mathrm{C}$ in humid atmosphere saturated with $5 \% \mathrm{CO}_{2}$.

\section{SRB assay}

This technique as first was described by Skehan et al. in 1990. The SRB assay was performed after $96 \mathrm{~h}$ exposure of the cultured cells to varying concentrations (ranging from 1 to $100 \mu \mathrm{g} / \mathrm{mL}$ ) of the tested substances. The reported derivatives as well as betulin 1 were dissolved in $10 \%$ dimethyl sulfoxide (DMSO) to concentration of $1 \mathrm{mg} / \mathrm{mL}$, and next diluted in culture medium to reach the required concentrations. DMSO as a solvent did not exert any inhibitory effect on cell proliferation. The cells fastened to the plastic were fixed mildly layering cold 50\% TCA (trichloroacetic acid, Aldrich-Chemie, Germany) on the top of the culture 
Scheme 1 Synthesis of derivatives 3-26. Reagents and conditions: $a \mathrm{RCOOH}, \mathrm{CH}_{2} \mathrm{Cl}_{2}$, DCC, DMAP, rt, $24 \mathrm{~h}$ or ROC (O)Cl, benzene, pyridine, rt, 24 $\mathrm{h} ; b$ PCC, $\mathrm{CH}_{2} \mathrm{Cl}_{2}, \mathrm{rt}, 2 \mathrm{~h}$

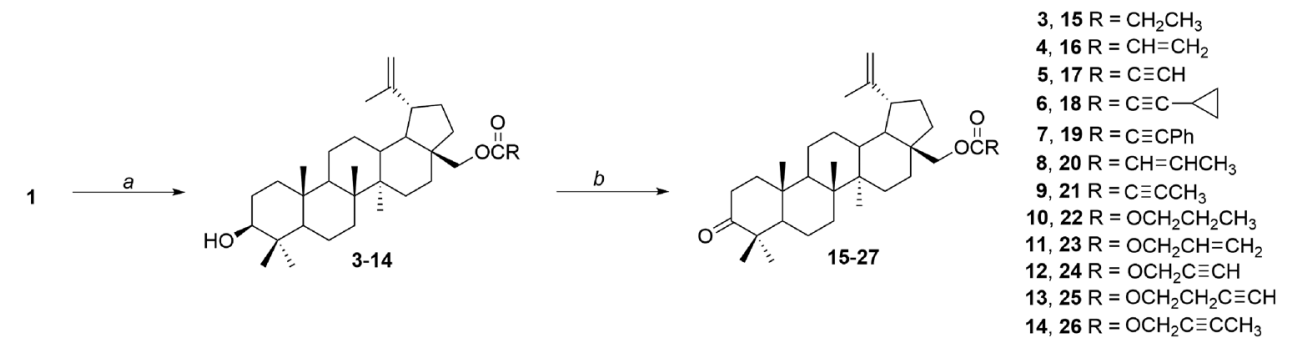

medium in each well. The plates were incubated at $4{ }^{\circ} \mathrm{C}$ for $1 \mathrm{~h}$ and then washed five times with tap water. The cells fixed with TCA were stained with $0.4 \%$ sulforhodamine B (SRB, Sigma, Germany) dissolved in $1 \%$ acetic acid (POCH, Gliwice, Poland) for $30 \mathrm{~min}$. The unbound dye was removed by rinsing four times with $1 \%$ acetic acid. The protein-bound dye was extracted with $10 \mathrm{mM}$ unbuffered tris base (POCH, Gliwice, Poland) and then determined the optical density at $540 \mathrm{~nm}$ in a computer-interfaced, 96-well microtiter plate reader Multiscan RC photometer (Labsystems, Helsinki, Finland).

The compounds in given concentration were examined in triplicates in each experiment which was repeated 3-5 times. The results of cytotoxic activity in vitro were expressed as an $\mathrm{IC}_{50}$ in $\mu \mathrm{g} / \mathrm{mL}$.

\section{MTT assay}

The MTT assay was used for the cytotoxicity screening against leukemia cells growing in suspension culture. This assay was performed after $96 \mathrm{~h}$ of the leukemia cells to varying concentrations (ranging from 1 to $100 \mu \mathrm{g} / \mathrm{mL}$ ) of the tested substances. The derivatives of betulin were dissolved in $10 \%$ DMSO to concentration of $1 \mathrm{mg} / \mathrm{mL}$, and next diluted in culture medium to reach the required concentrations. DMSO as a solvent did not exert any inhibitory effect on cell proliferation. During the last 3-4 h of incubation $20 \mu \mathrm{l}$ of MTT solution were added to each well (MTT: 3-(4,5-dimethylthiazol-2-yl)-2,5-diphenyl tetrazolium bromide; stock solution: $5 \mathrm{mg} / \mathrm{mL}$ ). The pale yellow MTT is reduced to a navy blue formazan in the mitochondria of living cells. At the end of incubation time, $80 \mu \mathrm{L}$ of the lysing mixture was added to each well (lysing mixture: $225 \mathrm{~mL}$ dimethylformamide, $67.5 \mathrm{~g}$ sodium dodecyl sulfate and $275 \mathrm{~mL}$ of distilled water). After $24 \mathrm{~h}$ are formed the crystals of formazan, which are insoluble in aqueous solutions. The formazan crystals had been dissolved. The optical densities were read on a Multiskan RC photometer at $570 \mathrm{~nm}$ wavelength.

The compounds in given concentration were examined in triplicates in each experiment which was repeated 3-5 times. The results of cytotoxic activity in vitro were expressed as an $\mathrm{IC}_{50}$ in $\mu \mathrm{g} / \mathrm{mL}$.

\section{In silico study}

The physicochemical properties of obtained compounds such as lipophilicity (cLogP), molecular mass (M), topological polar surface area (tPSA), hydrogen bond donors (HBD) and hydrogen bond acceptors (HBA) were calculated using the ACD/Labs software.

\section{Results and discussion}

\section{Chemistry}

The synthesis of betulin derivatives 3-14 was accomplished starting with betulin $\mathbf{1}$, which was isolated from birch bark of Betula verrucosa. The crude compound 1 was purified by flash-chromatography using a mixture of dichloromethane and ethanol as an eluent. Derivatives 3-14 were obtained according to our published procedures (Boryczka et al., 2013a, b). The esterification reactions of betulin $\mathbf{1}$ with carboxylic acids or chloroformates were performed with 49-86\% yields. The resulting monoesters 3-14 were oxidized with pyridinium chloroformate in dry dichloromethane to the derivatives of betulone 15-26 in 62-83\% yields. The synthesis of compounds 3-26 was presented via Scheme 1. All compounds were purified by column chromatography using the mixture of chloroform and ethanol. The chemical structures of new derivatives were determined on the basis of their ${ }^{1} \mathrm{H}-\mathrm{NMR},{ }^{13} \mathrm{C}-\mathrm{NMR}, \mathrm{IR}$ and $\mathrm{MS}$ spectra.

\section{Cytotoxic activity}

The newly compounds and betulin $\mathbf{1}$ were tested in vitro for their antitumor activity towards the following human cancer cell lines: T47D (human breast cancer), CCRF/CEM (human leukemia), SW707 (human colorectal), HL-60 (human promyelocytic leukemia) and murine leukemia P388 as well as BALB3T3 normal mouse fibroblasts cell line. In this study, cisplatin was used as a reference anticancer agent. The $\mathrm{IC}_{50}$ values $(\mu \mathrm{g} / \mathrm{mL})$ of the betulin derivatives are reported in Table 1 and Table 2 . The compounds 3-9, containing acyloxy group at the C-28 position, had 
Table 1 Cytotoxic activity $\left(\mathrm{IC}_{50}\right)$ of betulin $\mathbf{1}$, derivatives of betulin and cisplatin as a reference compound against the four cancer cell lines

\begin{tabular}{|c|c|c|c|c|c|}
\hline \multirow[t]{3}{*}{ Compound } & \multicolumn{5}{|c|}{ Cytotoxic activity $\mathrm{IC}_{50}[\mu \mathrm{g} / \mathrm{mL}]$} \\
\hline & \multicolumn{3}{|l|}{ Human } & \multicolumn{2}{|l|}{ Murine } \\
\hline & T47D & CCRF/CEM & SW707 & P388 & BALB3T3 \\
\hline Betulin 1 & $32.4 \pm 10.7$ & $10.9 \pm 5.5$ & $22.9 \pm 15.4$ & $5.5 \pm 3.3$ & $47.3 \pm 7.9$ \\
\hline $3^{\mathrm{a}}$ & $12.1 \pm 4.4$ & $8.1 \pm 0.9$ & $29.2 \pm 24.4$ & $3.3 \pm 0.8$ & $32.3 \pm 23.0$ \\
\hline 4 & $7.1 \pm 2.7$ & $19.6 \pm 9.5$ & $29.6 \pm 4.2$ & $9.9 \pm 5.9$ & $24.3 \pm 6.9$ \\
\hline $5^{\mathrm{a}}$ & $9.1 \pm 1.9$ & $0.02 \pm 0.001$ & $14.9 \pm 3.3$ & $0.4 \pm 0.1$ & $0.3 \pm 0.05$ \\
\hline 6 & $33.6 \pm 6.3$ & $16.5 \pm 8.5$ & $\mathrm{Neg}$ & $8.4 \pm 9.2$ & Neg \\
\hline $7^{\mathrm{a}}$ & Neg & $49.0 \pm 9.8$ & $\mathrm{Neg}$ & $\mathrm{Neg}$ & Neg \\
\hline 8 & $29.9 \pm 9.3$ & $28.0 \pm 21.6$ & $32.0 \pm 4.2$ & $5.1 \pm 4.9$ & $25.6 \pm 1.8$ \\
\hline 9 & $16.7 \pm 5.5$ & $2.1 \pm 0.3$ & $24.3 \pm 8.8$ & $2.9 \pm 1.4$ & $17.4 \pm 1.1$ \\
\hline 19 & Neg & $\mathrm{Neg}$ & $\mathrm{Neg}$ & $\mathrm{Neg}$ & $\mathrm{Neg}$ \\
\hline 24 & $23.3 \pm 3.5$ & $18.7 \pm 6.6$ & $\mathrm{Neg}$ & $30.3 \pm 11.8$ & Neg \\
\hline 25 & $29.8 \pm 10.7$ & $25.2 \pm 4.6$ & $\mathrm{Neg}$ & $3.8 \pm 1.9$ & Neg \\
\hline 26 & $79.2 \pm 5.2$ & $47.6 \pm 5.7$ & $\mathrm{Neg}$ & $18.3 \pm 12.9$ & $\mathrm{Neg}$ \\
\hline Cisplatin & $3.1 \pm 1.0$ & $2.0 \pm 0.5$ & $2.2 \pm 0.5$ & $0.5 \pm 0.3$ & $2.7 \pm 0.3$ \\
\hline
\end{tabular}

$\mathrm{Neg}$ negative in the concentration used

${ }^{a}$ Boryczka et al. (2013a, b)
$\mathrm{IC}_{50}$ values in the range of $0.02-49.0 \mu \mathrm{g} / \mathrm{mL}$ against the tested cell lines. In the series of the monoesters 3-9 the cytotoxic activity depends on the type of bond in the substituent at the C-28 position. The structure-activity relationships observed in the monoesters 3-9 indicates that rank order of the antiproliferative activity against the HL-60 cancer cell line, is as follows: propynoyl $>$ propenoyl $>2$ butynoyl $>$ propanoyl $>3$-cyclopropyl-2-propynoyl. Oxidation of the 3-hydroxyl group in compounds $\mathbf{4 , 6}$ and $\mathbf{1 0}$ to a carbonyl group led to an increase of activity against the HL-60 cancer cell line. The compounds 5 and $\mathbf{1 7}$ possessed the most potent activity, with $\mathrm{IC}_{50}$ value $0.3 \mu \mathrm{g} / \mathrm{mL}$ towards the human HL-60 cancer cell line. Moreover, these compounds exhibited the same antiproliferative activity as cisplatin. The betulones 24-26 with the acetylenic formate group at the C-28 position showed loss of activity against the human colorectal cell line (SW707) and normal mouse fibroblast cell line (BALB3T3). The rank order of the cytotoxic activity of the compounds 24-26 against T47D and CCRF/CEM cell lines, according to the nature of the formate substituent is as follows: propargyl $>3$-butynyl $>$ 2-butynyl.

The in silico study of tested compounds was performed by determination of Lipinski's rule of five and tPSA. The number of HBA and HBD significantly modulates the size of the polar surface area of molecule. The increase of the HBA number leads to higher affinity of the derivatives of betulone for P-glycoprotein. The most of betulin derivatives exhibited high values of molecular mass $(M>500)$ and lipophilicity $(\operatorname{cLog} P>5)$. However, the tPSA of all
Table 2 Cytotoxic activity $\left(\mathrm{IC}_{50}\right)$ of betulin $\mathbf{1}$, derivatives of betulin and cisplatin as a reference compound against the HL-60 cancer cell line. The parameters determined by computational methods such as lipophilicity $(\mathrm{cLog} \mathrm{P})$, molecular mass $(\mathrm{M})$, topological polar surface area (tPSA), hydrogen bond donors (HBD) and hydrogen bond acceptors (HBA)

\begin{tabular}{lcclllc}
\hline Compound & $\mathrm{IC}_{50}[\mu \mathrm{g} / \mathrm{mL}]$ & $\mathrm{cLogP}$ & $\mathrm{M}$ & tPSA $[\AA]$ & $\mathrm{HBD}$ & $\mathrm{HBA}$ \\
\hline Betulin 1 & $7.2 \pm 0.5$ & 6.63 & 442.71 & 40.46 & 2 & 2 \\
$\mathbf{3}$ & $29.3 \pm 3.4$ & 8.42 & 498.78 & 46.53 & 1 & 3 \\
$\mathbf{4}$ & $18.8 \pm 4.8$ & 8.23 & 496.76 & 46.53 & 1 & 3 \\
$\mathbf{5}$ & $0.3 \pm 0.004$ & 7.76 & 494.75 & 46.53 & 1 & 3 \\
$\mathbf{6}$ & $44.8 \pm 10.9$ & 8.85 & 534.81 & 46.53 & 1 & 3 \\
$\mathbf{9}$ & $24.5 \pm 1.9$ & 8.31 & 508.77 & 46.53 & 1 & 3 \\
$\mathbf{1 0}$ & $26.8 \pm 2.5$ & 8.39 & 528.80 & 55.76 & 1 & 4 \\
$\mathbf{1 1}$ & $14.9 \pm 3.9$ & 8.01 & 526.79 & 55.76 & 1 & 4 \\
$\mathbf{1 2}$ & $3.7 \pm 0.5$ & 7.64 & 524.77 & 55.76 & 1 & 4 \\
$\mathbf{1 5}$ & $33.7 \pm 5.5$ & 8.13 & 496.76 & 43.37 & 0 & 3 \\
$\mathbf{1 6}$ & $5.0 \pm 1.3$ & 8.07 & 494.75 & 43.37 & 0 & 3 \\
$\mathbf{1 7}$ & $0.3 \pm 0.06$ & 7.66 & 492.73 & 43.37 & 0 & 3 \\
$\mathbf{1 8}$ & $33.9 \pm 5.5$ & 8.61 & 532.79 & 43.37 & 0 & 3 \\
$\mathbf{2 1}$ & $29.5 \pm 5.4$ & 8.39 & 506.76 & 43.37 & 0 & 3 \\
$\mathbf{2 2}$ & $21.4 \pm 2.1$ & 8.23 & 526.79 & 52.60 & 0 & 4 \\
$\mathbf{2 3}$ & $28.4 \pm 1.6$ & 8.05 & 524.77 & 52.60 & 0 & 4 \\
$\mathbf{2 4}$ & $11.6 \pm 4.9$ & 7.68 & 522.76 & 52.60 & 0 & 4 \\
Cisplatin & $0.3 \pm 0.08$ & - & - & - & - & - \\
\hline
\end{tabular}

compounds is less than $140 \AA$, what determines high oral bioavailability (Abd El-Karim et al., 2015). 
In conclusion, the newly derivatives of betulin and betulone has been synthesized and characterized by spectroscopic analyses. Derivatives of betulin were tested for their antiproliferative activity against the five cancer cell lines. Several compounds exhibited a better cytotoxic effect than betulin $\mathbf{1}$. The most active derivatives $\mathbf{5}$ and $\mathbf{1 7}$ were 24-fold potent than betulin $\mathbf{1}$ against the human promyelocytic leukemia cell line (HL-60).

Acknowledgments This work was supported by the Medical University of Silesia in Katowice, Poland. Grant No KNW-1-002/N/5/0.

\section{Compliance with ethical standards}

Conflict of interest The authors declare that they have no competing interests.

Open Access This article is distributed under the terms of the Creative Commons Attribution 4.0 International License (http://creativecommons.org/licenses/by/4.0/), which permits unrestricted use, distribution, and reproduction in any medium, provided you give appropriate credit to the original author(s) and the source, provide a link to the Creative Commons license, and indicate if changes were made.

\section{References}

Abd El-Karim SS, Anwar MM, Mohamed NA, Nasr T, Elseginy SA (2015) Design, synthesis, biological evaluation and molecular docking studies of novel benzofuran-pyrazole derivatives as anticancer agents. Bioorg Chem 63:1-12

Alakurtti S, Mäkelä T, Koskimies S, Yli-Kauhaluoma J (2006) Pharmacological properties of the ubiquitous natural product betulin. Eur J Pharm Sci 29:1-13

Alakurtti S, Bergström P, Sacerdoti-Sierra N, Jaffe CL, YliKauhaluoma J (2010) Anti-leishmanial activity of betulin derivatives. J Antibiot 63:123-126

Boryczka S, Michalik E, Kusz J, Nowak M, Chrobak E (2013a) Lup20(29)-en-28-ol-3-one (betulone). Acta Cryst E69:o795-o796

Boryczka S, Bębenek E, Wietrzyk J, Kempińska K, Jastrzębska M, Kusz J, Nowak M (2013b) Synthesis, structure and cytotoxic activity of new acetylenic derivatives of betulin. Molecules 18:4526-4543

Chen JD, Yi RZ, Lin YM, Feng DQ, Zhou HC, Wang ZC (2011) Characterization of terpenoids from the root of Ceriops tagal with antifouling activity. Int J Mol Sci 12:6517-6528

Cole BJW, Bentley MD, Hua Y (1991) Triterpenoid extractives in the outer bark of Betula lenta (black birch). Hölzforschung 45:265-268

Diouf PN, Stevanovic T, Boutin Y (2009) The effect of extraction process on polyphenol content, triterpene composition and bioactivity of yellow birch (Betula alleghaniensis Britton) extracts. Ind Crops Prod 30:297-303
Gachet MS, Kunert O, Kaiser M, Brun R, Zehl M, Keller W, Munoz RA, Bauer R, Schuehly W (2011) Antiparasitic compounds from Cupania cinerea with activities against Plasmodium falciparum and Trypanosoma brucei rhodesiense. J Nat Prod 74:559-566

Grishko VV, Tarasova EV, Ivshina IB (2013) Biotransformation of betulin to betulone by growing and resting cells of the actinobacterium Rhodococcus rhodochrous IEGM 66. Process Biochem 48:1640-1644

Hase TA, Suokas E, Weckman A (1981) Dehydrogenation of triterpenoid alcohols in alkali melt. A short synthesis of the so called-Jasminol. Synth Commun 11:489-492

Hata K, Hori K, Takahashi S (2002) Differentiation- and apoptosisinducing activities by pentacyclic triterpenes on a mouse melanoma cell line. J Nat Prod 65:645-648

Hiroya K, Takahashi T, Miura N, Naganuma A, Sakamoto T (2002) Synthesis of betulin derivatives and their protective effects against the cytotoxicity of cadmium. Bioorg Med Chem 10:3229-3236

Koohang A, Majewski ND, Szotek EL, Mar AA, Eiznhamer DA, Flavin MT, Xu ZQ (2009) Synthesis and cytotoxicity of 2cyjano-28-hydroxy-lup-1-en-3-ones. Bioorg Med Chem Lett 19:2168-2171

Liu M, Yang S, Jin L, Hu D, Wu Z, Yang S (2012) Chemical constituents of the ethyl acetate extract of Belamcanda chinensis (L.) DC roots and their antitumor activities. Molecules 17:6156-6169

Mao DB, Feng YQ, Bai YH, Xu CP (2012) Novel biotransformation of betulin to produce betulone by Rhodotorula mucilaginosa. $\mathrm{J}$ Taiwan Inst Chem Eng 43:825-829

Mar AA, Koohang A, Majewski ND, Szotek EL, Eiznhamer DA, Flavin MT, Xu ZQ (2009) Synthesis and cytotoxicity of 28carboxymethoxy lupane triterpenoids. Preference of 28- $O$-acylation over 28-O-alkylation of betulin by ethyl bromoacetate. Chin Chem Lett 20:1141-1141

Orchel A, Kulczycka A, Chodurek E, Bębenek E, Borkowska P, Boryczka S, Kowalski J, Dzierżewicz Z (2014) Influence of betulin and 28-O-propynoylbetulin on proliferation and apoptosis of human melanoma cells (G-361). Postepy Hig Med Dosw 68:191-197

Reyes CP, Núnez MJ, Jiménez IA, Busserolles J, Alcaraz MJ, Bazzocchi IL (2006) Activity of lupine triterpenoids from Maytenus species as inhibitors of nitric oxide and prostaglandin $\mathrm{E}_{2}$. Bioorg Med Chem 14:1573-1579

Skehan P, Storeng R, Scudiero D, Monks A, Mcmachon J, Vistica D, Warren JT, Bokesch H, Kenney S, Boyol MR (1990) New colorimetric cytotoxicity assay for anticancer-drug screening. J Natl Cancer Inst 82:1107-1112

Sun IC, Shen JK, Wang HK, Cosentino LM, Lee KH (1998a) AntiAids agents. $32^{1}$. Synthesis and anti-HIV activity of betulin derivatives. Bioorg Med Chem Lett 8:1267-1272

Sun IC, Wang HK, Kashiwada Y, Shen JK, Cosentino LM, Chen CH, Yang LM, Lee KH (1998b) Anti-Aids agents. 34. Synthesis and structure-activity relationships of betulin derivatives as anti-HIV agents. J Med Chem 41:4648-4657

Tolstikov GA, Flekhter OB, Shultz EE, Baltina LA, Tolstikov AG (2005) Betulin and its derivatives. Chemistry and biological activity. Chem Sustain Develop 13:1-29 